\title{
CONTRASTES PRÁTICA DO LOBBY E ESTRATÉGIAS ADVOCACY: UMA ANÁLISE SOBRE O CASO BRASIL E SUA REGULAMENTAÇÃO
}

\section{ARTIGO ORIGINAL}

SILVA, Marcelo Nogueira Mallen da ${ }^{1}$

SILVA, Marcelo Nogueira Mallen da. Contrastes prática do lobby e estratégias advocacy: uma análise sobre o caso Brasil e sua regulamentação. Revista Científica Multidisciplinar Núcleo do Conhecimento. Ano 04, Ed. 08, Vol. 07, pp. 3547. Agosto de 2019. ISSN: 2448-0959

\section{RESUMO}

Este artigo analisa o potencial do lobby como instrumento democrático de representação de interesses e, por outro lado, a estrutura conhecida como advocacy, apontando as principais características, além dos problemas que podem ocasionar à luz do valor democrático das políticas sociais. O texto também discute a questão da regulamentação, focalizando os fatores que dificultam sua adoção no Brasil e iniciativas de engajamento, de modo a contribuir para o exercício do diálogo em razão dos manejos na efetivação de direitos.

Palavras-chave: Advocacy, Lobby, processo decisório, representação de interesses.

\footnotetext{
${ }^{1}$ Pós-graduado em Direito Empresarial e dos Negócios pela Universidade Cândido Mendes (UCAM-RJ), pós-graduado em Direito Imobiliário pelo Instituto Brasiliense de Direito Público (IDP-DF). Bacharel em Direito pela Universidade Veiga de Almeida (UVA-RJ).
} 


\section{INTRODUÇÃO}

O Brasil tem se tornado nas últimas décadas referência no debate internacional acerca da reforma da democracia graças a novas experiências participativas no desenho de políticas públicas, como o orçamento participativo e as comissões de legislação participativa (LAVALLE, HOUTZAGER, CASTELLO, 2006).

Como constatava Castells (2000, p. 49), estamos vivendo um momento histórico único de transformação social:

(...) considerando a história da humanidade como uma série de situações estáveis, pontuadas em intervalos raros por eventos importantes que ocorrem com grande rapidez e ajudam a estabelecer a próxima era estável. Pode-se afirmar que o final do século XX é um desses raros intervalos na história.

Esse novo paradigma determinou o surgimento de uma nova estrutura social, manifestada num novo modo de desenvolvimento e, com isso, ganharam força movimentos que torna mais profícua a tentativa de mudar opiniões/atitudes e, consequentemente, propagar melhorias no ambiente de interesse comum.

Todo esse potencial de participação, não se restringe a fase de mera discussão ou elaboração de proposições parlamentares e relatórios. Por esse ideal de eterna construção do debate coletivo, com a abordagem séria de questões tratadas hoje cada vez mais se exige a mobilização de uma grande variedade de agentes.

Segundo Lévy (1994, p. 61), "poderá se tornar um meio de exploração dos problemas, de discussão pluralista, de evidência de processos complexos, de tomadas de decisão e de avaliação dos resultados".

Para tal construção é que o presente artigo destaca a relevância e ineditismo da pauta para confirmar o aprendizado na disciplina ministrada pelo Professor Luis Inácio Lucena Adams. 


\section{ARCABOUÇO TEMÁTICO DO LOBBY VS. PRÁTICA DE ADVOCACY}

\subsection{ESCLARECENDO CONCEITOS}

Os conceitos são fundamentais quando tentamos expressar a forma como vemos o mundo e compreender o seu funcionamento. Um conceito só é útil quando é possível, por meio dele, expressar uma noção geral do objeto de estudo e, ao mesmo tempo, elaborar uma .

deia ou noção que contenha completamente o seu significado. Para isso, é necessário apresentar a sua especificidade, ou seja, o que o torna único.

Não à toa, formular conceitos precisos é especialmente importante para a área de relações intergovernamentais, haja vista que o lobbyl[2] é uma atividade abrangente e complexa ao mesmo tempo.

Enquanto a estratégia de policy advocacy ou simplesmente chamada como advocacy[3], ainda que represente outro estrangeirismo de origem igualmente inglesa pode assumir, pela experiência internacional, um forte engajamento e maior conscientização acerca de uma causa pública, como um processo de reivindicação de direitos que tem por direção influir na formulação e implementação de políticas que atendam às necessidades da população.

E, nesse contexto, mais adiante serão apresentadas as principais características de argumentação entre o lobby e a advocacy, na defesa de causas e direitos, como fatores de influência na criação de mecanismos efetivos, que tragam benefícios para os envolvidos, desde agentes privados, camadas da administração pública e, a sociedade acima de tudo.

\subsection{FACES POSITIVAS E NEGATIVAS DO LOBBY}

É sabido que os diferentes segmentos sociais não são igualmente capazes de se organizar ou de arregimentar recursos para formar lobbies em defesa de seus interesses. Quanto à capacidade de organização, a literatura indica que grupos pouco 
numerosos (por exemplo, os empresários de setores econômicos oligopolizados) têm maior facilidade que grupos grandes (por exemplo, os consumidores de um mercado competitivo ou os contribuintes) para resolver problemas de ação coletiva e constituir lobbies em busca de benefícios para seus membros (OLSON, 1999).

A partir dessa apresentação, as primeiras anotações oferecem uma conceituação padrão do que se entende pela expressão lobby seria a de "[f]ixar regras que possam nortear a fiscalização de um grupo sobre o outro que demanda um esforço coletivo, que nem sempre é de fácil execução" (OLIVEIRA, 2004, p. 219), ou, ainda, formado pelos "grupos de pressão promovem o interesse público" (RODRIGUES, 1982, p. 22).

\subsubsection{ATRIBUTOS DE CONFIANÇA (ASPECTOS POSITIVOS)}

Maria Cecília Gonçalves (2012) contextualiza o lobby como a prática de buscar acesso aos agentes políticos e fazer com que eles saibam das demandas de determinados segmentos da sociedade, usando pessoas (lobistas) e seus canais de contato junto aos órgãos de governos.

Para Roberto Lemos (1988, p. 49), "o lobby precisa ser visto como a organização e a operação de 'um eficiente canal de informações de mão dupla', entre a entidade que o apropria e o setor do que focaliza". Tendo como um dos indicativos que se utilizam para mensurar o poder econômico a "capacidade de o agente respectivo remover os obstáculos a que a atividade respectiva produza resultados positivos no menor tempo possível (CAMARGO, 2015, p. 76).

O contexto acima demonstra: (i) ser legítimo à iniciativa privada intervir na elaboração de políticas públicas que interessem à sociedade; (ii) a necessidade e a utilidade do lobby, que é reconhecido pelo triplo ganho, quando a sociedade, a iniciativa privada e o agente público se beneficiam.

Esse ganho plural somente será plausível se houver plena transparência nessa atividade. À guisa de esclarecimentos, Milton Seligman (2018) prefere chamar o lobby por seu próprio nome e não pelo eufemismo "relações governamentais", por exemplo. 


\subsubsection{CICLOS DE PULVERIZAÇÃO DA BOA-FÉ (ASPECTOS NEGATIVOS)}

Entretanto, há que se estabelecer uma observação acerca da linha tênue entre o lobby tido por lícito e sua versão mais rechaçada - o ilícito, está exatamente na dificuldade de se identificar qual intenção se pretende imprimir, uma vez que apesar da importância do lobby como instrumento de participação social e de representação de interesses, essa atividade é constantemente associada à corrupção fundada no abuso de poder que, nos ensinamentos de Luiz Alberto Santos (2007), ocorre quando um grupo de pressão abusa do poder público para obter ganhos privados.

A Controladoria-Geral da União (CGU) inclusive já emitiu Relatório do Grupo de Trabalho por meio da Portaria no 1.081, de 20 de junho de 2016, acerca da regulamentação do lobby, apontado que o mesmo é "legítimo", mas deve ser exercido dentro da estrita legalidade.

Os limites para seu exercício devem ser claros, bem como as regras para o relacionamento dos interessados com o poder público", sendo "importante para separar o lobby (atividade legítima de um ambiente democrático) de práticas obscuras e corruptas (que muitas vezes, erroneamente, são identificadas como lobby)"[4].

Esse abuso[5] consiste na extrapolação das tentativas de convencimento e de argumentação do lobby, chegando ao suborno e à intimidação dos servidores públicos e dos agentes políticos. $\mathrm{O}$ abuso de direito consiste, portanto, na falta praticada pelo titular de um direito, que ultrapassa os limites ou que deturpa a finalidade do direito que the foi concedido[6].

É nesse sentido que Washington Souza (p. 108), ensina:

Destacando-se nas "relações de poder" a modalidade do poder econômico, teremos aquelas relações jurídicas já permeadas de sentido de relações econômicas, cujas motivações deverão ajustar-se ao objetivo de justiça, sob pena de se contraporem aos direitos que devem 
assegurar. O exercício do poder econômico, portanto, far-se-á em obediência a um equilíbrio de interesses postos em jogo de acordo com uma linha traçada como delimitadora do justo e do injusto e que, definida pela lei jurídica, coincidirá com o lícito e o ilícito. A conduta lícita ou ilícita na prática do poder econômico, definirá, por sua vez, o seu uso ou seu abuso. (Grifos do próprio autor)

Ademais, de acordo com Murillo de Aragão (ARAGÃO, 2000 apud SANTOS, 2007), uma legislação de lobby eficiente para o modelo político brasileiro deveria buscar, entre outras coisas, identificar os grupos de pressão e estabelecer os deveres desses grupos diante dos órgãos e entidades estatais. Também seria objetivo da lei brasileira de lobby inibir a troca de favores e as vantagens concedidas a agentes e servidores públicos.

Castro Paixão citado por Luiz Alberto Santos (2007), ainda alerta quanto a imaturidade das instituições democráticas e da cultura política brasileira para recepcionar uma legislação de lobby à altura da legislação norte-americana:

Contudo, há que se compulsar os fatos, e a situação da Administração Pública no Brasil, seu elevado grau de corrupção e vulnerabilidade às pressões clientelistas ainda existentes, poderiam ter um efeito não desprezível sobre a aplicação dessa legislação. Embora não se possa considerar que haja baixa receptividade, no Brasil, a uma legislação voltada a assegurar que as atividades sejam submetidas a princípios de controle e transparência, e a uma regulamentação capaz de evitar abusos, corrupção e conflito de interesses, é preciso considerar o efeito que poderia advir da ausência de uma cultura política ainda amplamente favorável a controles rigorosos sobre o exercício das atividades de lobby.

O atual estágio da estruturação da burocracia pública brasileira, mesmo no plano federal, deixa ainda muito a desejar; o processo de formulação, implementação e avaliação de políticas públicas é prejudicado pela carência de quadros qualificados em nível adequado, pela 
descontinuidade administrativa, pela excessiva permeabilidade da gestão pública às nomeações de cargos em comissão por critérios clientelísticos ou relacionados ao sistema partidário, pela fragmentação do aparelho do Estado e, como destacam Paixão e Castro Santos, pela sua natureza multifacetada e sua porosidade em relação aos "interesses não excluídos do jogo de formulação e implementação de políticas".

Coexistem diferentes padrões corporativistas, "anéis burocráticos" e mecanismos informais de acesso e influência dos quais resulta a impressão de objetivos privados nas políticas públicas através das decisões de conselhos e agências burocráticas, especializadas ou não.

A exigência de utilização adequada do poder econômico não significa a necessidade de transformação dos interesses privados em interesses públicos. O que se vislumbra é que o agente privado não desenvolva seu poder em desfavor da coletividade ${ }^{[7]}$.

Foi com essa interpretação que se construiu aqui no Brasil o Projeto de Lei $(P L) n^{\circ}$ 1202/2007, assinado pelo deputado Carlos Zarattini (PT-SP), para regulamentar a atividade de lobby e de grupos de pressão junto ao setor público.

A justificativa guarda relação com inúmeras proposições de regulamentar a atuação dos "lobbies" na Administração Federal, com base na experiência internacional, notadamente nos Estados Unidos, Inglaterra, França e México, que demonstrariam a importância crescente do lobby como essência da democracia, na medida em que, possibilita, com transparência, a grupos de pressão e de interesse possam atuar organizadamente.

Reforça que só no Congresso dos Estados Unidos, mais de 3,7 mil entidades registradas atuam regularmente no lobby, cadastrando previamente seus representantes e prestando contas semestralmente de suas atividades, dos recursos que recebem e para quais finalidades os destinam.

No caso brasileiro, a prestação de contas seria anual e a qualquer momento, os credenciados para atuar como lobistas poderão ser convocados pelos presidentes das 
Casas do Poder Legislativo, pelo ministro do Controle e Transparência e pelo presidente do Tribunal de Contas da União para prestar esclarecimentos no tocante a sua atuação ou meios empregados em suas atividades.

Mais ainda, o desenvolvimento da sociedade civil reclama a institucionalização desses mecanismos, sujeitos ao controle da própria sociedade, dando ao tema tratamento consistente com o que a experiência internacional aponta como recomendável e atual, servindo de fonte delimitadora de todas as formas que comprometam a idoneidade do processo decisório público.

O PL tramita em regime de urgência no Plenário da Câmara dos Deputados, cuja matéria não foi apreciada na sessão de julgamento do dia 19.03.2019, em face do encerramento do ato sem início das votações e deliberação.

É preciso ressaltar aqui que a inserção no ordenamento jurídico de uma legislação de lobby, todavia, não é cem por cento suficiente para organizar e moralizar as relações entre grupos de pressão e o governo, assim como existem entraves previamente definidos na eventualidade de ser aprovada.

Nesse sentido, a legislação de lobby brasileira não deve assumir um caráter punitivo. Como alternativa até que o assunto amadureça com base na cultura adotada no país, seria a criação de códigos de conduta aliado a regulamentos complementares de controle e de fiscalização, regras que incentivem a transparência no setor público, a transparência nas parcerias entre privado e público, regras preventivas de conflito de interesses e de regras anticorrupção.

\subsection{CONTEMPORANEIDADE DO TERMO ADVOCACY}

$A d v o c a c y\left[{ }^{[8]}\right.$ é um termo que envolve um conjunto de significados, que advém da experiência de democracia norte-americana, sem tradução exata em português. Para Marcia Avner (2002), advocacy envolve identificar, adotar e promover uma causa, um esforço para moldar a percepção pública ou conseguir alguma mudança, seja esta através de lei ou não. Advocacy pode ser para indivíduos, para populações 
específicas ou causas, para o próprio interesse de uma organização ou setor ou para amplos benefícios de interesse público (BORIS; KREHELY, 2002).

Assim como se adaptaria dentro de um contexto de democracia deliberativa que fortalece o processo democrático ao trazer para o processo de deliberação organizações da sociedade civil que representam diversos grupos que expõem seus pontos de vista de políticas públicas e assuntos de seu interesse, tornando o processo mais participativo (DRYZEK, 2000).

Já Marlene Libardoni (2000, p. 02) apresenta a temática de advocacy pertencente ao campo das políticas públicas, com um instrumento de articulação para defesa de uma causa sob a perspectiva dos objetivos e interesses coletivos:

(...) advocacy tem um significado mais amplo, denotando iniciativas de incidência ou pressão política, de promoção e defesa de uma causa e/ou interesse, e de articulações mobilizadas por organizações da sociedade civil com o objetivo de dar maior visibilidade a determinadas temáticas ou questões no debate público e influenciar políticas visando à transformação da sociedade.

Na obra intitulada "Formação de Agenda: Método de Policy Advocacy para o Ensino de Políticas Públicas", Leonardo Secchi (2012, p. 33), define as atividades de advocacy como:

"Engajamento na influência da opinião púbica e das agendas da mídia, política e governamental sobre a relevância de algum problema público ou proposta de intervenção".

Dado que a função de advocacy implica em dar voz a uma mensagem ligada à defesa de uma causa, é imprescindível mencionar a obra "Coalizões em educação no Brasil: relação com o governo e influência sobre o Plano de Desenvolvimento da Educação (PDE)", com fins ilustrativos e de autoria de Lara Elena Simielli (2013, p. 572), pois serve como uma ferramenta de abordagem dedicada a temática de Advocacy Coalition Framework (ACF), assim interpretadas a título de coalizões advocatórias, as 
quais são entendidas como um modelo que busca compreender o processo político baseado no contexto da política ${ }^{[9],[10], ~ e ~ c o n c e i t u a d a s ~ c o m o: ~}$

(...) atores públicos e privados, provenientes de diversas instituições e níveis governamentais, que dividem um conjunto de crenças e valores comuns e que buscam manipular as regras, orçamentos e recursos humanos governamentais visando a atingir seus objetivos a longo prazo.

Em termos práticos, advocacy poderia ser descrito como o processo organizado e planejado de informar e influenciar tomadores de decisão, por meio de conscientização e engajamento de outros atores da sociedade, tendo como objetivo promover mudança (ou manutenção) de uma política pública de interesse amplo, baseada em evidências concretas ${ }^{[11]}$.

Para elucidar a questão comentada, vale repetir as palavras de Luiz Inácio Adams (2017), em entrevista ao portal Consultor Jurídico, ao trazer como conceito do que chama de advocacy republicano, advogar para interesses, para projetos ${ }^{[12]}$.

A insuficiência de vasta literatura no Brasil deste termo não impede, porém, de encontrar referências referente a participação da sociedade civil com mais frequência, assim como temas de participação e deliberação, sociedade civil e espaços públicos, democracia participativa, entre outros que se aproximem do papel de advocacy em políticas públicas.

De outra sorte, em que pese se confirme na coordenação de ações de defesa de interesses considerando os aspectos jurídicos, políticos, econômicos e sociais como dito anteriormente, não foram encontrados registros de agenda regulatória para reconhecimento de sua aplicação ou mesmo vestígios que conduzam na reação de sistema jurídico capaz de produzir uma norma reguladora.

\section{CONCLUSÃO}

A formulação de mecanismos e estratégias para gerar o chamado desenvolvimento tem sido uma constante nas receitas propostas pelos agentes privados, órgãos e 
entidades públicas somadas a atuação mais presente da sociedade no painel intelectual das políticas públicas planejadas pelo Estado.

Tais mecanismos se encontram em um nível de discurso permanente no qual, de diferentes formas, se alude ao objetivo de garantir melhor qualidade de vida com o citado desenvolvimento participativo.

Para se constituir uma alternativa coerente ainda se mostra urgente e crucial buscar explicações para os fenômenos do tempo presente e construir estratégias de políticas dispostas a promover e gerar processos amplos de integração com o viés publicista para não só favorecer interesses individualizados, mas combater desigualdades e a precarização de direitos fundamentais.

Tais medidas podem influir e evitar a polarização dos debates atuais. Mas o que se observa é que não existem soluções simples para as questões das desigualdades e das diferenças, dos direitos individuais e das entidades de grupos. Posicionar tais questões como conceitos opostos pode ter como significado perder o ponto de suas interconexões.

O enfrentamento da questão das desigualdades exige cada vez mais que se estabeleçam interconexões entre o individual e o coletivo, para, fortificado com novos instrumentais, seja na utilização do lobby (desde que feito com seriedade, honestidade, sensatez e, principalmente, que objetive o bem comum), ou pela campanha de advocacy, que priorizem em suas ações a consideração das determinações dos problemas a serem combatidos, para que possam planejar, priorizar e desenvolver ações que apresentem verdadeiramente impactos na realidade posta e que promovam a mudança social esperada.

\section{REFERÊNCIAS}

ADAMS, Luiz Inácio Lucena. Responsabilização de advogado por planejamento tributário é intolerável. Entrevista concedida a Breno Grillo. Consultor Jurídico 
(CONJUR), 2017. Disponível em: <https://www.conjur.com.br/2017-set-30/entrevistaluis-inacio-adams-ex-advogado-geral-uniao>. Acesso em: 24 jun. 2019.

ANPAD, 2007. Disponível em: <http://www.anpad.org.br/admin/pdf/APS-A1916.pdf>. Acesso: 24 jun. 2019.

AVNER, Marcia. The Lobbying and Advocacy Handbook for Nonprofit Organizations: Shaping Public Policy at the State and Local Level. Minnesota: Amherst H. Wilder Foundation, 2002.

BORIS, Elizabeth T.; KREHELY, Jeff. Civic Participation and Advocacy. In: Lester. M. Salamon. The State of Nonprofit America. Washington DC: Brookings Institution Press, 2002.

BRASIL. Controladoria-Geral da União (CGU). Brasília, 2019. Relatório sobre Lobby. Em: <https://www.cgu.gov.br/Publicacoes/institucionais/arquivos/relatorio_lobby.pdf>. Acesso em: 24 jun. 2019.

Câmara dos Deputados (CÂMARA). Brasília, 2019. Projeto de Lei no 1202/2007. Disciplina a atividade de "lobby" e a atuação dos grupos de pressão ou de interesse e assemelhados no âmbito da Administração Pública Federal. Disponível em:

$<$ https://www.camara.leg.br/proposicoesWeb/fichadetramitacao?idProposicao=35363 1. Acesso em: 24 jun. 2019.

BRELÁZ, Gabriela de. Advocacy das Organizações da Sociedade Civil: Principais Descobertas de um Estudo Comparativo entre Brasil e Estados Unidos. XXXI Encontro

BRUNA, Sérgio Varella. Poder econômico e a conceituação do abuso em seu exercício. São Paulo: Revista dos Tribunais, 2001.

CAMARGO, Ricardo Antonio Lucas. À corrupção no Brasil a luz do Direito Econômico. Revista Acadêmica. Recife: UFPE, v. 87, n. 1, 2015. 
CASTELLS, Manuel. A sociedade em rede. Economia, Sociedade e Cultura, vol. 1. São

Paulo: Paz e Terra, 2000.

CAVALIERI FILHO, Sérgio. Programa de Direito do Consumidor. São Paulo: Atlas, 2008.

DEMO, Pedro. Política social, educação e cidadania. São Paulo: Papirus, 2007.

DIAS, Rafael de Brito. A trajetória da política científica e tecnológica brasileira: um olhar a partir da análise de política. Tese (Doutorado em Política Científica e Tecnológica) - UNICAMP, 2009.

DRYZEK, John S. Deliberative Democracy and Beyond. Liberals, Critics, Contestations. Oxford: Oxford University Press, 2000.

GONÇALVES, Maria Cecília Nunes. Regulamentação do lobby no Congresso Nacional brasileiro: o estudo comparado do modelo norte-americano. Monografia (Especialização em Processo Legislativo) - CEFOR. Brasília, 2012.

GOZETTO, Andréa; MACHADO, Leandro. Ainda é necessário esclarecer conceitos: Lobby $x$ Advocacy. Cause. São Paulo, sem data. Disponível em: $<$ http://www.cause.net.br/ainda-e-necessario-esclarecer-conceitos-lobby- $x$ advocacy/>. Acesso em: 24 jun. 2019.

LAVALLE, Adrián Gurza; HOUTZAGER, Peter Pim; CASTELLO, Graziela. Representação Política e Organizações Civis: Novas Instâncias de Mediação e os Desafios da Legitimidade. Revista Brasileira de Ciências Sociais, vol. 21. n. 60, 2006.

LEMOS, Roberto Jenkins. Lobby: direito democrático. São Paulo: Sagra, 1988.

LÉVY, Pierre. A inteligência coletiva. São Paulo: Edições Loyola, 1994. 
LIBARDONI, MARLENE. Fundamentos teóricos e visão estratégica da advocacy. Disponível em: <https://periodicos.ufsc.br/index.php/ref/article/view/11936/11202>. Acesso: 24 jun. 2019.

MANCUSO, Wagner Pralon; GOZETTO, Andréa Cristina Oliveira. Lobby e Políticas Públicas apud LUKIC, Melina Rocha, TOMAZINI, Carla (Coord). As Ideias também importam: abordagem cognitiva e políticas públicas no Brasil. Curitiba: Juruá, 2013.

OLIVEIRA, Andréa. Cristina de Jesus. Lobby e Representação de Interesses: Iobistas e seu impacto sobre a representação de interesses no Brasil. Tese (Doutorado em Ciências Sociais) - UNICAMP. São Paulo, 2004.

OLSON, Mancur. A lógica da ação coletiva. São Paulo: Edusp, 1999.

RODRIGUES, Ricardo. A Regulamentação do Lobby no Brasil: Leitura crítica de um Projeto de Lei. Revista de Administração Pública, Rio de Janeiro, n. 30, jan./fev. 1996.

SANTOS, Luiz Alberto dos. Regulamentação das atividades de lobby e seu impacto sobre as relações entre políticos, burocratas e grupos de interesse no ciclo de políticas públicas - análise comparativa dos Estados Unidos e Brasil. Brasília, 2007.

SECCHI, Leonardo. Formação da Agenda: Método de Policy Advocacy para Ensino de Políticas Públicas. Revista de Administração Pública e Gestão Social, Viçosa, v. 4, n. 1, abr./jul. 2012. O artigo completo pode ser visualizado no caminho: <https://periodicos.ufv.br/ojs/apgs/article/view/4046/2276>. Acesso: 24 jun. 2019.

SELIGMAN, Milton; MELLO, Fernando (Org.). Lobby Desvendado. Democracia, Políticas Públicas e Corrupção no Brasil Contemporâneo, Rio de Janeiro: Editora Record, 2018.

SEMIELLI, Lara Elena Ramos. Coalizões em educação no Brasil: relação com o governo e influência sobre o Plano de Desenvolvimento da Educação (PDE). Revista de Administração Pública, Rio de Janeiro, v. 47, n. 3, mai./jun. 2013. 
SOUZA, Washington Peluso Albino de. Estudos de Direito Econômico, vol. 1. Belo Horizonte: Movimento Editorial da Faculdade de Direito da UFMG, 1995, p. 458.

SOUZA, Luiz Ricardo de; SECCHI, Leonardo. A Política Científica e Tecnológica de Santa Catarina: análise a partir do modelo de coalizões de defesa. Revista da Administração Pública, Rio de Janeiro, v. 48, n. 4, jul./ago. 2014 [online]. Disponível para consulta na íntegra pelo endereço eletrônico: $<$ http://www.scielo.br/scielo.php?pid=S003476122014000400007\&script=sci_abstract\&tlng=pt>. Acesso: 24 jun. 2019.

2. De forma bem compilada, é possível conceituar lobby para início dos trabalhos como "a defesa de interesses junto a membros do poder público que tomam decisões". In: MANCUSO, Wagner Pralon; GOZETTO, Andréa Cristina Oliveira. Lobby e Políticas Públicas apud LUKIC, Melina Rocha, TOMAZINI, Carla (Coord.). As Ideias também importam: abordagem cognitiva e políticas públicas no Brasil. Curitiba: Juruá, 2013.

3. O Fundo de População das Nações Unidas (FNUAP), aponta como referência que se trata de "trabalhar para a sensibilização dos gestores públicos e da sociedade civil sobre a importância de temas de interesse social”. In: DEMO, Pedro. Política social, educação e cidadania. São Paulo: Papirus, 2007.

4. Para leitura na íntegra o conteúdo pode ser consultado no endereço eletrônico: <https://www.cgu.gov.br/Publicacoes/institucionais/arquivos/relatorio_lobby.pdf>. Acesso em: 24 jun. 2019.

5. Sérgio Cavalieri Filho (2008, p. 88), contribui trazendo suas notas quanto a: "expressão práticas abusivas é, evidentemente, genérica e, portanto, assim deve ser interpretada, para que nada Ihe escape. Deve, pois, ser considerado abusivo tudo o que afronte a principiologia e a finalidade do sistema protetivo do consumidor, bem assim se relacione à noção de abuso do direito".

6. SOUZA, Washington Peluso Albino de. Estudos de Direito Econômico, vol. 1. Belo Horizonte: Movimento Editorial da Faculdade de Direito da UFMG, 1995, p. 458. 
7. Acerca desta dicotomia entre interesses públicos e privados, Sérgio Bruna entende que os interesses coletivos devem sempre prevalecer sobre os interesses individuais, "não devendo prevalecer o poder econômico que se apresente como entrave ao desenvolvimento social e aos fatores que objetivam a consecução dos ideais de justiça" (Bruna, 2001, p. 147).

8. Sem obviamente esgotar o assunto, vale citar a doutrina prefacial de Gabriela de Brelàz, defensora de que o termo advocacy irrompe fronteiras conceituais jurídicas do campo de estudo do direito, considerando que: "[p]or advocacy entendemos o ato de identificar, adotar e promover uma causa. É um esforço para moldar a percepção pública ou conseguir alguma mudança seja através de mudanças na lei, mas não necessariamente".

9. Contribuem nesse capítulo Luiz Ricardo Souza e Leonardo Secchi (2014) ao darem destaque que a terminologia advocacy vem acompanhada da expressão Advocacy Coalition Framework (ACF), enfatizando aspectos como o aprendizado e o comportamento das coalizões, bem como identificando as alterações na política, assim calculado em longos períodos de tempo.

10. Esse modelo se encaixa aos fenômenos envolvidos nas mudanças políticas que Rafael Dias havia abordado em conclusão de seu doutoramento (2009, p. 30): "podem ser entendidas como grupos de atores que se organizam, formal ou informalmente, como o objetivo de exercer pressão sobre determinada política pública, e assim, influenciar seu resultado".

11. Ver também em: <http://www.cause.net.br/ainda-e-necessario-esclarecerconceitos-lobby-x-advocacy/>. Acesso em: 24 jun. 2019.

12. Entrevista completa disponível no endereço eletrônico: <https://www.conjur.com.br/2017-set-30/entrevista-luis-inacio-adams-ex-advogadogeral-uniao>. Acesso em: 24 jun. 2019.

Enviado: Julho, 2019. 
Aprovado: Agosto, 2019. 